\title{
Determinants of inter-pregnancy interval in Ogbomoso: an unmet need for contraceptive usage
}

\author{
Kola M. Owonikoko*, Olanrewaju Adeniji, Oluwaseyi F. Oke, \\ Adegboyega A. Fawole, Adetunji O. Adeniji
}

Department of Obstetrics and Gynaecology, Ladoke Akintola University of Technology, Ogbomoso, Oyo State, Nigeria.

Received: 29 December 2014

Accepted: 02 February 2015

\author{
*Correspondence: \\ Dr. Kola M. Owonikoko, \\ E-mail: musliudin@yahoo.co.uk
}

Copyright: ( $)$ the author(s), publisher and licensee Medip Academy. This is an open-access article distributed under the terms of the Creative Commons Attribution Non-Commercial License, which permits unrestricted non-commercial use, distribution, and reproduction in any medium, provided the original work is properly cited.

\begin{abstract}
Background: Worldwide maternal mortality has witnessed a significant reduction in the last 2 decades and this has partly been due to the increase contraceptive use and with consequent reduction in inter-pregnancy interval. The aim of this study was to determine the factors influencing inter-pregnancy intervals among pregnant women attending antenatal care and their contraception needs

Methods: A cross-sectional study on pregnant women with at least one previous delivery attending antenatal clinic of a Teaching Hospital using a structured questionnaire

Results: The mean \pm SD age of the respondents was $27.4 \pm 0.6(20-44)$ years. The majority (76\%) were multiparous. Vaginal delivery $(91 \%)$ and live birth $(86.9 \%)$ were reported in the last pregnancy. Most respondent $64.4 \%$ had their last confinement more than 2years. Marital status $(p<0.05)$, educational status $(p=0.003)$, average income per month $(\mathrm{p}=0.003)$, parity $(\mathrm{p}=0.02)$, outcome of previous pregnancy $(\mathrm{p}=0.01)$, mode of delivery $(\mathrm{p}=0.001)$ and duration of breastfeeding $(\mathrm{p}=0.001)$ were factors which showed significant association with inter-pregnancy interval. Awareness of modern contraceptive methods was reported by $65.4 \%$, with $60 \%$ and $32.6 \%$ wanting to resume contraceptive use immediately and within 6-12months of delivery respectively.

Conclusions: The study showed inter-pregnancy interval of twenty-four months. Obstetric and socio-demographic factors were significantly associated with inter-pregnancy interval. Effective health information and reproductive education would encourage effective contraception uptake and better maternal and baby outcome.
\end{abstract}

Keywords: Inter-pregnancy intervals, Unmet need, Contraceptive usage

\section{INTRODUCTION}

Globally maternal mortality has witnessed a significant reduction in the last twenty years and this has partly been due to the increase contraceptive use, with consequent reduction in unintended pregnancies. ${ }^{1}$ Amy Tsui and others noted that in developing countries, the risk of prematurity and infant mortality doubles when pregnancy recurs within six months of previous birth. ${ }^{1}$
The Nigeria National Demographic and Reproductive Health survey (NDHS) of 2008 showed that birth spacing of at least twenty four months reduces infant death. ${ }^{2}$ The survey showed that one quarter of infants in Nigeria are born less than two years after a previous birth and infants born less than two years after a previous birth have a particularly high infant mortality rate estimated at 135deaths per 1000 live births as against 44 per 1000 live births for infants born four or more years of previous birth. $^{2}$ 
Globally, standardization of what constitutes short or long inter-pregnancy birth interval has been difficult though some authorities have tried to assign particular time interval. ${ }^{3}$ Bao Ping Zhu noted ideal inter-pregnancy birth interval to be $18-23$ months based on favourable pregnancy outcome and long term infant survival. ${ }^{4}$ However, the Nigeria NDHS put the mean birth interval in Nigeria at thirty-one months. ${ }^{2}$

Stephannosson in his study in Sweden noted that diverse inter-play of factors influence inter-pregnancy birth intervals among couples, factors such as outcome of previous pregnancies viz. abortion, stillbirth and delivery of live baby. ${ }^{5}$ It was also noted that inter-pregnancy interval tended to be longer following a live birth as against pregnancies ending with abortion and stillbirth. ${ }^{5}$ Age of the woman has been shown to be an important factor influencing inter-pregnancy birth intervals and it was observed that younger women tended to have longer inter-pregnancy birth interval relative to older women.,6 The mode of delivery has also been shown to impact on timing of inter-pregnancy birth interval as women who had spontaneous vaginal delivery have shorter interval as against those who had instrumental deliveries and Caesarean section. ${ }^{7}$ The events of the puerperium equally have profound effect on timing of inter-pregnancy birth interval, as well as the duration of breastfeeding with the attendant contraceptive advantage. ${ }^{5}$

Kaharuza from Denmark observed that the gynaecological characteristics of a woman such as pattern of menstrual cycle, whether regular or irregular influences inter-pregnancy interval, as women with irregular cycle have higher likelihood of short interpregnancy interval due to unpredictability of ovulation. ${ }^{8}$

Socio-economic factors were shown by Ruth Mace in Addis Abba, Ethiopia to influence fertility. While most studies have shown that fertility and wealth are negatively correlated, however Ruth showed that women from high socio-economic class have shorter interpregnancy birth interval as against women from low socioeconomic class with longer inter-pregnancy birth interval. ${ }^{6,9}$

Regular attendance at a family planning clinic and type of contraception used has a significant correlation to birth interval. ${ }^{10}$ This result from persistently positive reinforcement about gains derivable from contraception and the women being able to share experiences with each other.

The aim of this study is to determine the factors influencing inter-pregnancy intervals of pregnant women attending antenatal care and their contraception needs.

\section{METHODS}

This study was carried out at Ladoke Akintola University of Technology Teaching Hospital (LTH), Ogbomoso, a tertiary health institution in a semi-urban town in southwest Nigeria. It was a cross- sectional study among consenting pregnant women that have had at least one parous experience regardless of the outcome. The study period was between March and December, 2013. The sample size was calculated based on the NDHS 2008 of contraceptive prevalence of South-west Nigeria at $21 \%{ }^{2,11}$ A total sample size of 255 was derived. However 400 women were recruited for the study on assumption of high rate of attrition based on the intimate nature of the study.

The data collection instrument was a multi-items structured questionnaire consisting of three sections. Section A was employed to collect information on respondents age, educational status and their partners, tribe, occupation of respondents and their partners, religion, home ownership structure and average income per household. The section B sought information about the past obstetrics history of respondents - parity, outcome of last pregnancy, mode of delivery, duration of breastfeeding and time interval between last delivery till now. The section $\mathrm{C}$ was employed to review menstrual history and contraceptive use and needs of the respondents. For clarity, the questionnaire was pre-tested among 25 pregnant women at the Alao Akala Primary Health Centre (PHC) - an outreach obstetric unit of LTH Ogbomoso, after which it was re-structured and ambiguous questions were re-phrased. The questionnaire was self-administered by the literate women while the illiterate women had theirs administered by the research assistants who read the questions to them and chose the answers based on their opinion. The exclusion criteria for the study were any non-consenting pregnant woman or any woman without prior parous experience.

The consent of the respondents was obtained verbally during the health talk at the counseling sessions during the visits. The questionnaires were also introduced with a request for consent and freedom of participation was duly stressed to the women. The women that did not consent to participate in the study were in no way discriminated against with respects to medical treatment of their conditions. Also, approval for the study was given by the LTH ethical review committee.

\section{Statistical analysis}

The raw data from the field was vetted for irregularities and duly edited making appropriate adjustments where necessary. Analysis of data was by computer using SPSS (Statistical Package for Social Sciences) SPSS version 20 for Windows evaluation version. Data were presented using tables. Cross-tabulation of variables was performed and chi square was used to establish statistical association between variables. The level of statistical significance was set at $\mathrm{p}<0.05$. 


\section{RESULTS}

Four hundred women were interviewed, however only 390 questionnaires were valid for analysis.

The age of the respondents ranged between 20-44 years with a mean age of $27.4 \pm 0.6$. Majority of the respondents $(80.3 \%)$ are Yorubas, while $11.0 \%$ are Igbos, $5.4 \%$ of respondents are Hausas and other tribes like the Tivs and Urhobos constituted $3.3 \%$ of the study population.

Almost $60 \%$ of respondents are Christians while $38.7 \%$ are Muslims and only 3.3\% of the respondents practice Traditional religion.

More than half of respondents $(55.1 \%)$ have at least a secondary level of education, $27.9 \%$ have tertiary level of education. The proportion of respondents with additional qualification to tertiary education represents $1.3 \%$ of the study population, with $15.6 \%$ having primary level of education.

Close to $90 \%$ of sampled women were married, $8 \%$ are single and $4.9 \%$ of the women cohabit presently with their partners. While $28 \%$ are currently separated from their partners, $2.3 \%$ are widowed with $3.1 \%$ currently divorced from their partners.

The occupational distribution of respondents showed that $56.4 \%$ are semi-skilled with $25.6 \%$ of respondents in the skilled workforce and $17.9 \%$ are unskilled.

Majority of respondents $69.0 \%$ average income per month is less than N18, 000 (\$100), 23.6\% have an average income between N18000-N40000 and only 7.2\% earns above N40, 000 (\$222.2) per month. The proportion of respondents' partners that earn less than $\mathrm{N} 18,000(\$ 100)$ are $7.4 \%$, while $21.8 \%$ earn between N18, 000-N40, 000. Most of the respondents' partners $(70.8 \%)$ earns above N40, 000. Most of the respondents live in rented accommodation $(72.8 \%)$ and $18.1 \%$ live in their personal house, while $8.7 \%$ live with friends and other family members (Table 1).

While $15.9 \%$ have had at least one parous experience, about $76 \%$ have between 2-4 parous experience and only $8.2 \%$ have had more than 4 parous experiences. Majority of the respondents $(86.9 \%)$ had live birth as the outcome of their last pregnancy, while $6.7 \%$ and $6.4 \%$ of respondents had stillbirth and abortion as the outcome of their last pregnancy respectively. The commonest mode of delivery was by spontaneous vaginal delivery $(91.0 \%)$ and this was followed by Caesarean section (7.2\%) and women who had instrumental vaginal delivery were $1.8 \%$. While majority of sampled women breastfed their babies, $2.3 \%$ did not practice any form of breastfeeding, $69.3 \%$ of the respondents breastfed their babies for between six to twelve months, $21 \%$ breastfed their babies for less than six months, while $7.4 \%$ breastfed their babies for between twelve to twenty four months. The majority of the women had inter-pregnancy interval of more than twenty-four months $(64.4 \%)$ and this was closely followed by inter-pregnancy interval of between thirteen to twenty four months at $26.4 \%$. The proportion of respondents with inter-pregnancy interval of between six to twelve months is $6.9 \%$, while $2.3 \%$ had interpregnancy interval of less than six months (Table 2).

Table 1:Socio-demographic characteristics.

\begin{tabular}{|c|c|c|}
\hline Characters & $\begin{array}{l}\text { Number } \\
(n=390)\end{array}$ & $\begin{array}{l}\text { Percentage } \\
(\%)\end{array}$ \\
\hline \multicolumn{3}{|l|}{ Age group (years) } \\
\hline $20-24$ & 79 & 20.3 \\
\hline $25-27$ & 164 & 42.1 \\
\hline $30-34$ & 94 & 24.1 \\
\hline $35-39$ & 46 & 11.8 \\
\hline $40-44$ & 7 & 1.8 \\
\hline \multicolumn{3}{|l|}{ Religion } \\
\hline Christian & 227 & 58.2 \\
\hline Muslim & 151 & 38.7 \\
\hline Traditionalist & 12 & 3.1 \\
\hline \multicolumn{3}{|l|}{ Educational status } \\
\hline Primary/Arabic & 61 & 15.6 \\
\hline Secondary & 215 & 55.1 \\
\hline Tertiary & 109 & 27.9 \\
\hline $\begin{array}{l}\text { Additional } \\
\text { Qualification }\end{array}$ & 5 & 1.3 \\
\hline \multicolumn{3}{|l|}{ Occupation } \\
\hline Unskilled & 70 & 17.9 \\
\hline Semiskilled & 220 & 56.4 \\
\hline Skilled & 100 & 25.6 \\
\hline \multicolumn{3}{|l|}{ Marital status } \\
\hline Single & 3 & 8 \\
\hline Cohabit & 19 & 4.7 \\
\hline Married & 339 & 87 \\
\hline Widowed & 9 & 2.3 \\
\hline Divorced & 12 & 3.1 \\
\hline Separated & 8 & 2.1 \\
\hline \multicolumn{3}{|c|}{ Average monthly income } \\
\hline $\begin{array}{l}\text { Below N18,000 } \\
(\$ 100)\end{array}$ & 269 & 69.0 \\
\hline N 18,000-N40,000 & 92 & 23.6 \\
\hline$>\mathrm{N} 40,000(\$ 222.2)$ & 29 & 7.4 \\
\hline \multicolumn{3}{|l|}{ Accommodation } \\
\hline Personal & 72 & 18.5 \\
\hline Rented & 284 & 72.8 \\
\hline Others & 34 & 8.7 \\
\hline
\end{tabular}

The contraceptive use awareness showed that $65.4 \%$ of respondents were aware of modern method of contraceptives, $34.6 \%$ were not aware of modern method of contraceptives. Majority $(68.7 \%)$ will like to use a contraceptive, $31.3 \%$ of the respondents are not interested in using a contraceptive. The proportion of those that will like to use it immediately after delivery were $58.8 \%$ 
while $32.6 \%$ prefers using it between six to twelve months after delivery (Table 3).

While statistical significance exist between interpregnancy interval and the respondents' marital status, educational status, average income per month, parity, outcome of previous pregnancy, mode of delivery and duration of breastfeeding (Table 4).

Table 2: Obstetric performance of the study population.

\begin{tabular}{|c|c|c|}
\hline $\begin{array}{l}\text { Obstetric } \\
\text { character }\end{array}$ & $\begin{array}{l}\text { Frequency } \\
(n=390)\end{array}$ & Percentage ( \%) \\
\hline \multicolumn{3}{|l|}{ Parity } \\
\hline 1 & 62 & 15.9 \\
\hline $2-4$ & 296 & 75.9 \\
\hline$>4$ & 32 & 8.2 \\
\hline \multicolumn{3}{|c|}{ Outcome of last pregnancy } \\
\hline Live & 339 & 86.9 \\
\hline Still birth & 26 & 6.7 \\
\hline Abortion & 25 & 6.4 \\
\hline \multicolumn{3}{|c|}{ Mode of delivery of last pregnancy } \\
\hline SVD & 355 & 91 \\
\hline $\mathrm{C} / \mathrm{S}$ & 28 & 7.2 \\
\hline $\begin{array}{l}\text { Instrumental } \\
\text { Vaginal Delive }\end{array}$ & 7 & 1.8 \\
\hline \multicolumn{3}{|c|}{ Duration of breast feeding } \\
\hline $\begin{array}{l}\text { No breast } \\
\text { feeding }\end{array}$ & 9 & 2.3 \\
\hline$<6$ months & 82 & 21 \\
\hline 6-12 months & 270 & 69.3 \\
\hline 12-24 months & 29 & 7.4 \\
\hline \multicolumn{3}{|c|}{ Inter-pregnancy interval } \\
\hline$<6$ months & 9 & 2.3 \\
\hline $6-12$ months & 27 & 6.9 \\
\hline 13-24 months & 103 & 26.4 \\
\hline$>24$ months & 251 & 64.4 \\
\hline
\end{tabular}

Table 3: Contraceptive awareness and desire for use.

\begin{tabular}{|lll|}
\hline Contraception & $\begin{array}{c}\text { Frequency } \\
(\mathrm{n=390)}\end{array}$ & $\begin{array}{l}\text { Percentage } \\
(\%)\end{array}$ \\
\hline Awareness & & \\
\hline Yes & 255 & 65.4 \\
\hline No & 135 & 34.6 \\
\hline Desire for use & \\
\hline Yes & 268 & 68.7 \\
\hline No & 122 & 31.3 \\
\hline How soon to use after delivery & \\
\hline Immediately & 229 & 58.8 \\
\hline 6-12 months & 127 & 32.6 \\
\hline 12-24 months & 27 & 6.9 \\
\hline$>24$ months & 7 & 1.8 \\
\hline
\end{tabular}

Table 4: Cross-tabulation of various characteristics of respondents' versus inter-pregnancy interval.

\begin{tabular}{|c|c|c|c|}
\hline Characteristics & $\begin{array}{l}\text { df (degree } \\
\text { of } \\
\text { freedom) }\end{array}$ & $\begin{array}{l}\text { Chi } \\
\text { square }\end{array}$ & P-Value \\
\hline Age group & 12 & 19.25 & 0.082 \\
\hline Religion & 6 & 6.30 & 0.406 \\
\hline Marital status & 15 & 25.03 & $0.05^{*}$ \\
\hline $\begin{array}{l}\text { Educational } \\
\text { status }\end{array}$ & 9 & 24.60 & $0.003^{*}$ \\
\hline Occupation & 6 & 6.90 & 0.331 \\
\hline $\begin{array}{l}\text { Educational } \\
\text { status of partner }\end{array}$ & 9 & 6.28 & 0.709 \\
\hline $\begin{array}{l}\text { Occupation of } \\
\text { partner }\end{array}$ & 9 & 9.83 & 0.364 \\
\hline $\begin{array}{l}\text { Average } \\
\text { income per } \\
\text { month }\end{array}$ & 9 & 26.61 & $0.002 *$ \\
\hline $\begin{array}{l}\text { Average } \\
\text { income } \\
\text { partner }\end{array}$ & 9 & 9.76 & 0.370 \\
\hline $\begin{array}{l}\text { Partiy } \quad \text { of } \\
\text { woman }\end{array}$ & 12 & 82.62 & $0.001 *$ \\
\hline $\begin{array}{l}\text { Mode of } \\
\text { delivery of last } \\
\text { pregnancy }\end{array}$ & 6 & 62.22 & $0.001 *$ \\
\hline $\begin{array}{l}\text { Outcome of last } \\
\text { pregnancy }\end{array}$ & 6 & 83.15 & $0.001 *$ \\
\hline $\begin{array}{l}\text { Duration of } \\
\text { breast feeding }\end{array}$ & 9 & 59.39 & $0.001 *$ \\
\hline
\end{tabular}

* Statistically significant at $\mathrm{p}$ value $<0.05$

\section{DISCUSSION}

The study has clearly shown that there is some correlation between certain socio-demographic characteristics of the woman and inter-pregnancy interval. The study was carried out in Ogbomoso, a major town in Oyo state, south-west of Nigeria that is predominantly inhabited by the Yoruba ethnic group. This could account for its influence on inter-pregnancy birth interval in the study environment. The Yoruba in southwestern Nigeria are one of the most educated tribes in Nigeria and many women have access to lots of information on ways of adequately spacing their births. This was equally shown in the works of Nathalie Auger et al of Montreal Canada about the impact of neighborhood clusters on inter-pregnancy interval, ${ }^{12}$ though the influence was explained on the basis of marital status against educational status in their study.

Most studies have shown that younger women tend to have longer inter-pregnancy interval as against older women, ${ }^{5-6}$ same was found from this study where young women (20-29 years) accounted for $56.6 \%$ women who postponed their inter-pregnancy interval beyond 24 months, this probably was because large proportion are married with secondary level of education and their 
desire to further their education may be responsible for this observation.

Among older women, higher incidences of morbidity tend to complicate pregnancies, ${ }^{13}$ with higher likelihood of Caesarean delivery and instrumental deliveries. This may account for longer inter-pregnancy birth interval as well as natural decline in fertility above 30-35 years of age, ${ }^{14}$ which may make spontaneous conception difficult.

This study demonstrated that certain obstetric performance could influence inter-pregnancy interval, factors like parity, outcome of last pregnancy, mode of delivery in the last pregnancy and duration of breastfeeding. Women who exclusively breastfed their babies for at least six months have a $98 \%$ chance of not conceiving within this period (Bellagio consensus). ${ }^{15}$ This can positively lengthen inter-pregnancy interval as most respondents from this study $97.5 \%$ breastfeed their babies between 6-24 months, this is still in keeping with observation from Nigeria National Demographic and Reproductive Health Survey (NDHS 2008) where breastfeeding practices is almost universal. ${ }^{2}$

The women with Caesarian section and instrumental deliveries have longer inter-pregnancy interval on account of longer period to recovery and consequent late resumption of sexual activity. Episiotomy given during instrumental deliveries equally delays initiation of sexual activity. Women that undergo Caesarean delivery are usually advised to delay onset of new pregnancy till about twelve to eighteen months, ${ }^{14}$ this is to prevent risk of uterine rupture in subsequent pregnancies and attendant morbidity and probable mortality that may accompany this both for the woman and the fetus.

The outcome of prior pregnancies also was statistically significant from this study and this may be on account of compelling need by the couple to replace lost pregnancy and consequently a short inter-pregnancy interval. Also since breastfeeding is not undertaken among this group of women and with the resultant inability to benefit from the contraceptive advantage of breastfeeding, ovulation might resume earlier in these group of women. A similar pattern was equally noted by Hajian et al. from Iran. ${ }^{10}$

The mean inter-pregnancy interval of this study is twenty-four months and almost comparable with a similar study in United States, ${ }^{4}$ but lowers than thirty-one months quoted by NDHS 2008. The apparent disparity between this result and that of the Demographic Survey might be on account of smaller sample size. The National Demographic survey result represents the national average among Nigeria's six geo-political zones. ${ }^{2}$ A lot more people on the basis of reproductive health knowledge now realize that adequate spacing of birth ensures infant survival for a present baby.

The contraceptive awareness from this study of $65.4 \%$ may be at variance with some other local studies especially Ashekun Olarinmoye et al., showed high awareness of contraceptive usage $(90 \%) .{ }^{16}$ The probable reason for this may be nature of the two locations where the studies were carried out. While Ashekun's study was done in Osogbo, a state capital and seat of government and with access to better infrastructural facilities and migration of diverse people into it, Ogbomoso is more of semi-urban community in comparison to Osogbo. However, despite the low level of awareness of modern contraception by the respondents, $68.7 \%$ of them show strong desire to use contraception. Infect, almost twothird of them want to start effective contraception immediately after delivery and almost all $(91.4 \%)$ want to be on modern contraception within 6-12 months of delivery. This finding further buttress previous revelation of effective health information and education on uptake of contraception by the clients. ${ }^{16}$

\section{CONCLUSIONS}

This study revealed the inter-pregnancy interval of twenty-four months. Obstetric and socio-demographic factors such as marital status, educational level, average monthly earnings, parity, mode and outcome of delivery of last pregnancy and duration of breastfeeding are significantly affect the inter-pregnancy interval. Effective health information and reproductive education would encourage effective contraception uptake and better maternal and baby outcome.

\section{Funding: No funding sources \\ Conflict of interest: None declared \\ Ethical approval: The study was approved by the Institutional Ethics Committee}

\section{REFERENCES}

1. Tsui AO, McDonald-Mosley R,Burke AE. Family planning and the burden of unintended pregnancies. Epidemiol Rev. 2010;32(1):152-74.

2. National population commission (Nigeria): Nigeria Demographic and Health Survey. M.D National population commission 2008. Available at www.unicef.org/nigeria/ng_publication_DHS_2008. Accessed on 6th October, 2013.

3. Donaghy M. Fourth champions meeting on optimal birth spacing by the Catalyst consortium, October 2003. Available at www.rhcatalyst.org/site/ Accessed on 6th October, 2013..

4. Zhu BP, Rolfs RT, Nangle BE,Horan JM. Effect of the interval between pregnancies on perinatal outcomes. N Engl J Med. 1999;340(8):589-94.

5. Stephansson O, Dickman PW,Cnattingius S. The influence of interpregnancy interval on the subsequent risk of stillbirth and early neonatal death. Obstet Gynecol. 2003;102(1):101-8.

6. Nabukera SK, Wingate MS, Salihu HM, Owen J, Swaminathan S, Alexander GR, et al. Pregnancy spacing among women delaying initiation of 
childbearing. Arch Gynecol Obstet. 2009;279(5):677-84

7. Stamilio DM, DeFranco E, Pare E, Odibo AO, Peipert JF, Allsworth JE, et al. Short interpregnancy interval: risk of uterine rupture and complications of vaginal birth after cesarean delivery. Obstet Gynecol. 2007;110(5):1075-82.

8. Kaharuza FM, Sabroe S,Basso O. Choice and chance: determinants of short interpregnancy intervals in Denmark. Acta Obstet Gynecol Scand. 2001;80(6):532-8.

9. Gurmu E,Mace R. Fertility decline driven by poverty: the case of Addis Ababa, Ethiopia. J Biosoc Sci. 2008;40(3):339-58.

10. Hajian-Tilaki KO, Asnafi N,Aliakbarnia-Omrani F. The patterns and determinants of birth intervals in multiparous women in Babol, northern Iran. Southeast Asian J Trop Med Public Health. 2009;40(4):852-60.

11. Armitage P, Berry G, Mathew JNS: Statistical methods in Medical Research, 4th edition. Blackwell Oxford. 2002.

12. Auger N, Daniel M, Platt R, Luo Z-C, Wu Y,Choiniere R. The joint influence of marital status, interpregnancy interval, and neighborhood on small for gestational age birth: a retrospective cohort study. BMC Pregnancy and Childbirth. 2008;8(1):7.

13. Dutta DC. Special cases in Obstertrics. In: Dutta DC, DC Dutta's Textbook of Obstetrics.7th Edition. New central Book Agency (P) Ltd;2011:327-44.

14. Kwawukume EY, Emuveyan EE. Infertility Comprehensive Gynaecology in the tropics. Graphic Packaging Limited; 2005:333-45.

15. Kennedy KI,Visness CM. Contraceptive efficacy of lactational amenorrhoea. Lancet. 1992;339(8787):227-30.

16. Asekun-Olarinmoye E, Adebimpe W, Bamidele J, Odu O, Asekun-Olarinmoye I,Ojofeitimi E. Barriers to use of modern contraceptives among women in an inner city area of Osogbo metropolis, Osun state, Nigeria. Int J Womens Health. 2013;5:647-55.

DOI: $10.5455 / 2320-1770 . i j \operatorname{rog} 20150406$

Cite this article as: Owonikoko KM Adeniji O, Oke OF, Fawole AA, Adeniji AO. Determinants of interpregnancy interval in Ogbomosho: an unmet need for contraceptive usage. Int J Reprod Contracept Obstet Gynecol 2015;4:316-21. 